\title{
Pulsed Excimer (KrF) Laser Melting of Amorphous and Crystalline Silicon Layers
}

\section{Citation}

Narayan, J., C. W. White, M. J. Aziz, B. Stritzker, and A. Walthuis. 1985. Pulsed excimer (KrF) laser melting of amorphous and crystalline silicon layers. Journal of Applied Physics 57 (2): 564-567.

\section{Published Version}

http://dx.doi.org/10.1063/1.334738

\section{Permanent link}

http://nrs.harvard.edu/urn-3:HUL.InstRepos:3708236

\section{Terms of Use}

This article was downloaded from Harvard University's DASH repository, and is made available under the terms and conditions applicable to Other Posted Material, as set forth at http:// nrs.harvard.edu/urn-3:HUL.InstRepos:dash.current.terms-of-use\#LAA

\section{Share Your Story}

The Harvard community has made this article openly available.

Please share how this access benefits you. Submit a story.

\section{Accessibility}




\title{
Pulsed excimer $(K r)$ laser meltho of amorphous and crystalline sillicon layers ${ }^{a)}$
}

\author{
J. Narayan, C. W. White, M. J. Aziz, B. Stritzker, ${ }^{\text {() }}$ and A. Walthuis ${ }^{\text {b) }}$ \\ Solid State Division, Oak Ridge National Laboratory, Oak Ridge, Tennessee 37831
}

(Received 29 March 1984; accepted for publication 24 July 1984)

\begin{abstract}
We have investigated depth of melting as a function of pulse energy density in amorphous and crystalline silicon layers. The melting threshold for $\mathrm{KrF}$ laser pulses $\lambda=0.249 \mu \mathrm{m}$, $\left.\tau=24 \times 10^{-9} \mathrm{~s}\right)$ in amorphous ( 7660 - $\AA$-thick) and crystalline silicon layers were determined to be $0.16 \pm 0.02$ and $0.75 \pm 0.05 \mathrm{~J} \mathrm{~cm}^{-2}$, respectively. The formation of fine- and largepolycrystalline regions was clearly identified in the amorphous silicon layers for energy densities below that needed for complete annealing. The role of explosive recrystallization in the formation of the fine polycrystalline region is discussed.
\end{abstract}

\section{INTRODUCTION}

Pulsed-laser processing of semiconductors for a number of device applications and for a variety of surface modifcations is now well established. The major obstacle to the development of pulsed-laser processing for practical applications has been the lack of suitable lasers. The pulsed lasers most commonly used for semiconductor processing have been ruby $(0.694 \mu \mathrm{m})$, frequency-doubled Nd-YAG $(0.532$ $\mu \mathrm{m})$ or glass $(0.531 \mu \mathrm{m})$, and alexandrite $(0.700-0.818 \mu \mathrm{m})$ lasers. However, these solid-state lasers have certain limitations primarily related to spatial inhomogeneity, low-pulse repetition rates (due to the heat dissipation problems in the insulating crystals) and low overall energy conversion effciency. These problems limit throughput and increase cost of devices. Recently, it was shown that a gas laser (excimer) such as $\mathrm{XeCl}(0.308 \mu \mathrm{m})$ was considerably superior to solid lasers in terms of spatial homogeneity and pulse repetition rates for semiconductor processing. ${ }^{1,2}$ The term excimer, derived from the words excited and dimer, refers to a diatomic gaseous molecule which is bound in the excited state but repulsive in the ground state. The excimer lasers, which are in the ultraviolet range, contain a reduced coherence due primarily to a large number of transverse modes thus avoiding interference effects at the surface of the samples. The solid-state lasers have a high coherence leading to spatial inhomogeneities. The purpose of this paper is twofold: first, to show that the $\mathrm{KrF}(0.248 \mu \mathrm{m})$ pulsed laser is as efficient as the $\mathrm{XeCl}$ laser in removing displacement damage; second, the melting characteristics and melting threshold of amorphous and crystalline layers have been studied. During the melting of amorphous layers, two distinct regions containing large (LP) and fine (FP) polycrystals are created. The LP region has been shown to be formed by normal plane-front melting and resolidification back to the free surface, whereas the $\mathrm{FP}$ region has been shown to be formed primariiy by the movement of a thin liquid layer away from the free surface

\footnotetext{
"Research sponsored by the Division of Materials Sciences, U.S. Department of Energy under contract DE-AC05-840R21400 with Martin Marietta Energy Systems, Incorporated.

b) Institut für Festkörperforschung, Kernforschungsanlage Jülich, D-5170, Jülich, Federal Republic of Germany.
}

during explosive recrystallization. ${ }^{3-5}$ The details of explosive recrystallization and bulk nucleation and growth of crystallites in the formation of the FP region are discussed. These results are compared with those obtained from heatflow calculations.

\section{EXPERIMENT}

Silicon single crystals (having $\langle 100\rangle$ orientation, 2-6 $\Omega \mathrm{cm}, 500 \mu \mathrm{m}$ thick, Czochralski grown) were implanted with 200 - and $350-\mathrm{keV}^{30} \mathrm{Si}^{+}$ions to a dose of $1.5 \times 10^{16}$ and $2.0 \times 10^{16} \mathrm{~cm}^{-2}$, respectively. The specimens were kept at liquid-nitrogen $\left(\mathrm{LN}_{2}\right)$ temperature during implantation. The as-implanted specimens contained amorphous layers followed by a band of dislocation loops. Some of the silicon specimens were implanted with $175-\mathrm{keV}^{30} \mathrm{Si}^{+}$ions to a dose of only $2.0 \times 10^{14} \mathrm{~cm}^{-2}$, at room temperature. These specimens contained only dislocation loops distributed to a depth of $4500 \AA$. The ion-implanted specimens were irradiated with $\mathrm{KrF}$ excimer laser $(\lambda=0.249 \mu \mathrm{m})$ pulses with energy density ranging from 0.1 to $2.0 \mathrm{~J} \mathrm{~cm}^{-2}$. The shape of the pulse was trapezoidal with full width at half maximum being $24 \times 10^{-9} \mathrm{~s}$. The laser provided a uniform beam $(<5 \%$ energy over $3 \times 3 \mathrm{~cm}^{2}$ area) with excellent pulse-to-pulse reproducibility $(<2 \%)$. The laser system was operated at an energy of $1 \mathrm{~J} /$ pulse, with an attainable throughput of $\sim 500$ $\mathrm{cm}^{2} \mathrm{~s}^{-1}$. Microstructural changes and phase transformations, which provided detailed information on annealing and melting phenomena, were studied by cross-section and planview electron microscopy in a Philips EM-400 electron microscope. The widths of LP and FP regions were determined as a function of pulse energy density. The microstructural features of the FP and $\mathrm{LP}$ regions were analyzed and the mechanisms of formation of these regions were derived. The role of explosive recrystallization and bulk nucleation and growth of microcrystallites was determined from the characteristics of the microstructures.

\section{RESUETS AND DISCUSSION}

The cross-section TEM results obtained from $350-\mathrm{keV}$ ${ }^{28} \mathrm{Si}^{+}$implants (dose $=2.0 \times 10^{16} \mathrm{~cm}^{-2}$ at $\mathrm{LN}_{2}$ ) are shown in Fig. 1. The as-implanted samples contained 7660 - $\AA$-thick amorphous layer followed by a 300 - $\AA$-wide band of disloca- 

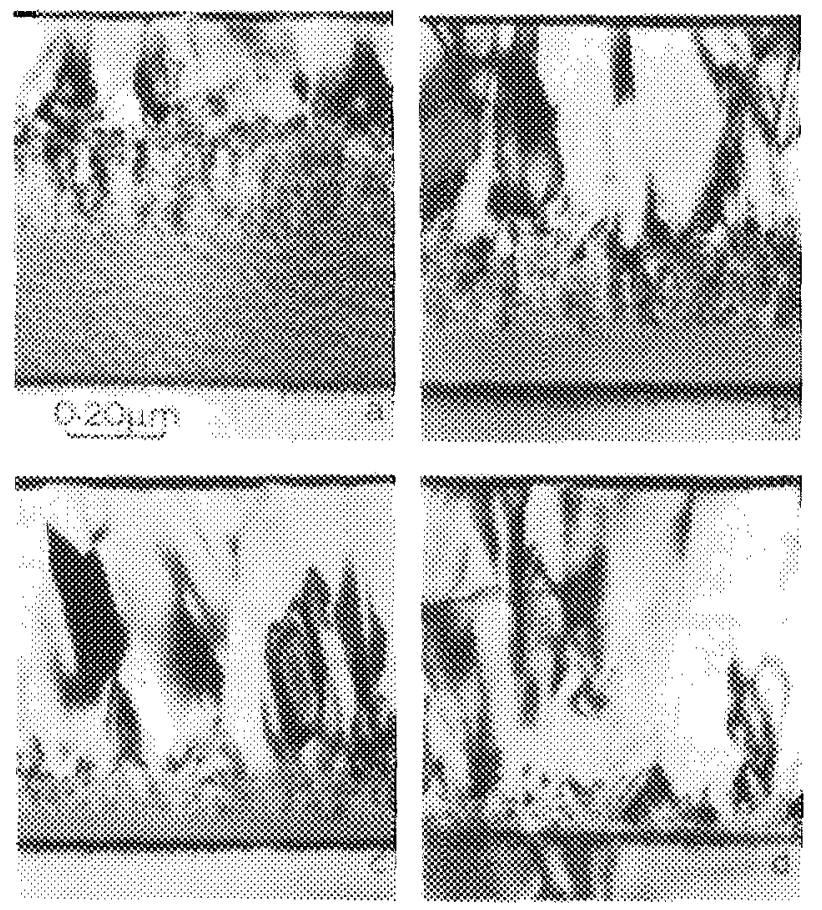

FIG. 1. Cross-section TEM micrographs from ion-implanted $(350-\mathrm{keV}$ $\left.{ }^{28} \mathrm{Si}^{+}, 2.0 \times 10^{16} \mathrm{~cm}^{-2}\right),(100)$ silicon after pulsed-laser irradiations with the following energy density: (a) 0.50, (b) 0.80 , (c) 1.0 , and (d) $1.20 \mathrm{~J} \mathrm{~cm}^{-2}$.

tion loops. After irradiation with laser pulses, we observed the formation of two distinct regions; near the surface, the large-polycrystalline (LP) region and, below it, the fine-polycrystalline (FP) region. The detailed characteristics and formation of these regions were studied as a function of pulse energy density. Figure 1 shows selected results as an example. After irradiation with a $0.5-\mathrm{J} \mathrm{cm}^{-2}$ pulse, the top $2460-$ $\AA$-thick layer turned into a LP region, which was followed by a 2200 - $\AA$-wide FP region [as shown in Fig. 1(a)]. This specimen contained some background contamination gener-
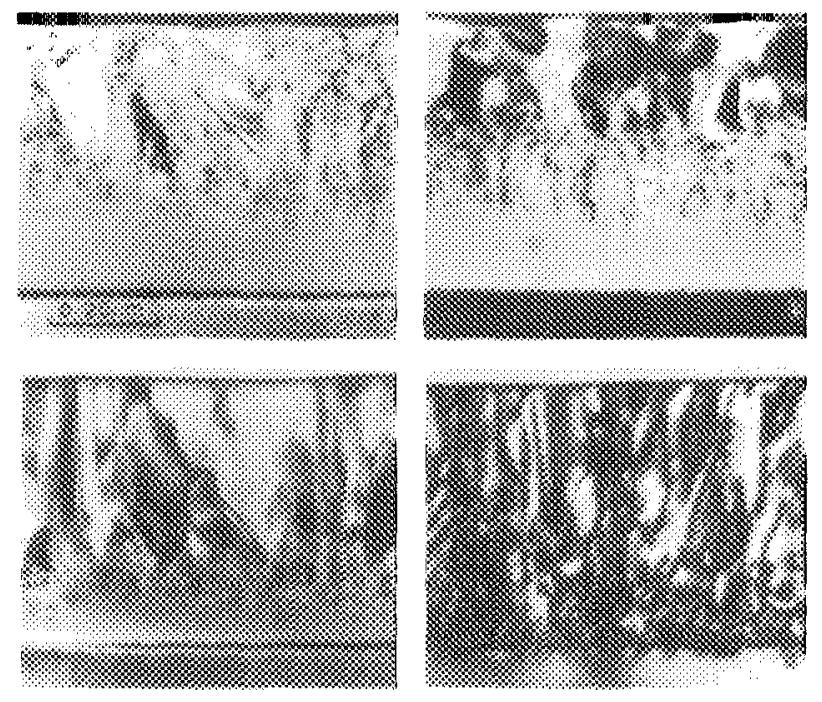

FIG. 2. Cross-section TEM micrographs from ion-implanted (200-keV $\left.{ }^{28} \mathrm{Si}^{+}, 1.5 \times 10^{16} \mathrm{~cm}^{-2}\right),(100)$ silicon after pulsed-laser irradiation with the following energy density: (a) 0.20 , (b) 0.50 , (c) 0.80 , and (d) $1.20 \mathrm{~J} \mathrm{~cm}^{-2}$.

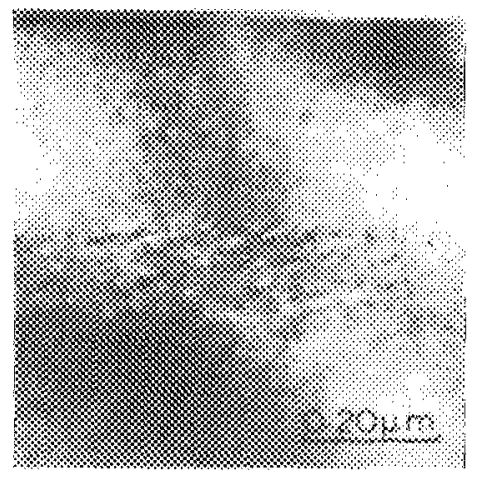

FIG. 3. Cross-section TEM micrograph from ion-implanted $(175 \mathrm{keV}$ $\left.{ }^{30} \mathrm{Si}^{+}, 2.0 \times 10^{14} \mathrm{~cm}^{-2}\right),(100)$ silicon after irradiation with pulse energy density of $1.40 \mathrm{~J} \mathrm{~cm}^{-2}$.

ated during ion thinning. Still, sharp boundaries between the LP and FP regions, and the FP and the underlying amorphous layers are clearly visible. Figure $1(\mathrm{~b})$ shows results after irradiation with a $0.08-\mathrm{J} \mathrm{cm}^{-2}$ pulse. The thickness of the LP and FP regions were determined to be 4700 and 1900 $\AA$, respectively. After irradiation with $1.0-\mathrm{J} \mathrm{cm}^{-2}$ pulse [Fig. 1(c)], the thickness of the LP region increases to $6150 \AA$, whereas the FP region thickness decreases to $1100 \AA$. At $1.20 \mathrm{~J} \mathrm{~cm}^{-2}$, the $L P$ region extends to the amorphous-dislocation band boundary and the entire amorphous layer turns into a large poly region.

Figure 2 shows selected results for $200-\mathrm{keV}^{30} \mathrm{Si}^{+}$-implanted specimens (dose $=1.5 \times 10^{16} \mathrm{~cm}^{-2}$ at $\left.\mathrm{LN}_{2}\right)$. The asimplanted specimens contained 5000- $\AA$-thick amorphous layer followed by a $200-\AA$-wide band of dislocation loops. After irradiation with a $0.20-\mathrm{J} \mathrm{cm}^{-2}$ pulse, a 400 - $\AA$-thick top layer turned into a LP region followed by a 3400 - $\AA$-wide FP region, as shown in Fig. 2(a). Figure 2(b) shows results after irradiation with a $0.50-\mathrm{J} \mathrm{cm}^{-2}$ pulse, where the thickness of the LP region increases to $2000 \AA$ and that of the FP region decreases to $2000 \AA$. At $0.80 \mathrm{~J} \mathrm{~cm}^{-2}$, the thickness of the LP region increases further to $3500 \AA$ and the thickness of the FP region decreases further to $700 \AA$ [Fig. 2(c)]. When the pulse energy density was increased to $1.0 \mathrm{~J} \mathrm{~cm} \mathrm{~cm}^{-2}$, the LP region extended to a depth of $5000 \AA$ corresponding to the amorphous dislocation band boundary with no concomitant FP region. The thickness of the LP region was found to remain unchanged at $1.10 \mathrm{~J} \mathrm{~cm}^{-2}$. However, at $1.20 \mathrm{~J} \mathrm{~cm}^{-2}$ the melt front just intersected the underlying dislocation band. The dislocation loops intersected by the melt front grow back to the surface, as shown in Fig. 2(d). A "complete" annealing of ion implantation damage was obtained above $1.20-\mathrm{J} \mathrm{cm}^{-2}$ pulse energy density. This characteristic of depth of melting with pulse energy density is thought to be due to the lower melting point of amorphous silicon. ${ }^{6-9}$

Figure 3 shows results on melting or annealing of crystalline layers. For these experiments, the (100) $\mathrm{Si}$ specimens were irradiated with $175-\mathrm{keV},{ }^{30} \mathrm{Si}^{+}$ions to a dose of only $2.0 \times 10^{14} \mathrm{~cm}^{-2}$ at room temperature. For these ion implantation conditions, only dislocation loops of average size 100 $\AA$ were observed with no amorphous regions; the loops were distributed to a depth of $4500 \AA$. The removal of interstitial dislocation loops provided evidence for melting, thus the 
loops serve as markers to determine the depth of melting. The depth of melting was determined in the range of pulse energy density $0.60-2.0 \mathrm{~J} \mathrm{~cm}^{-2}$. A typical cross-section TEM micrograph from these specimens after $1.40-\mathrm{J} \mathrm{cm}^{-2}$ irradiation is shown in Fig. 3, where a complete removal of loops has occurred in the top 3000 - $\AA$-wide region. A complete removal of dislocation loops in the annealed $3000-\AA$ wide region and a sharp boundary between the annealed and unannealed regions are consistent with a first-order phase transition involving melting.

In Fig. 4, we plot the annealing/melting results for both amorphous and crystalline specimens. The threshold for melting for amorphous silicon was found to be $0.16 \pm 0.02$ $\mathrm{cm}^{-2}$; this value decreased with increasing amorphous layer thickness. The threshold for melting for crystalline silicon was determined to be $0.75 \pm 0.05 \mathrm{~J} \mathrm{~cm}^{-2}$. The difference in melting thresholds is due mainly to the reduced thermal conductivity of $\alpha \mathrm{Si}^{6,8}$ In the case of amorphous silicon, the thickness of the LP region increased linearly with pulse energy density whereas the thickness of the FP + LP region showed a rapid initial rise followed by a saturation at the original amorphous layer thickness. Note that the slope of the LP curve (amorphous silicon) is higher than that of crystalline melting curves, indicating mainly the role of a reduced latent heat of melting of $\alpha \mathrm{Si}^{4} \mathrm{~A}$ heat-flow program written by M. O. Thompson ${ }^{10}$ was used to calculate the initial depth of melting in amorphous and crystalline specimens. These calculations showed a linear increase in depth of melting with laser pulse energy density, the depth of melting corresponding to the thickness of the LP region alone. ${ }^{5}$

In the following, we discuss the mechanism of formation of the FP region below the LP region in the case of amorphous silicon. Figure 5 shows plan-view (a) and crosssection (b) micrographs from 350-keV implants after irradiation with $0.30-\mathrm{J} \mathrm{cm}^{-2}$ pulse. The cross-section micrograph shows 1000 - $\AA$-thick $L P$ region at the top followed by a 2700 $\AA$-wide FP region. The microstructure in the underlying FP region is characteristic of explosive recrystallization, as clearly delineated (by arrows) in the plan-view micrograph of Fig. 5(a). It was found that the region is formed primarily by explosive recrystallization for low-pulse energy densities in which case the width of the FP is larger or comparable to that of the LP region. Futher evidence of explosive recrystal-

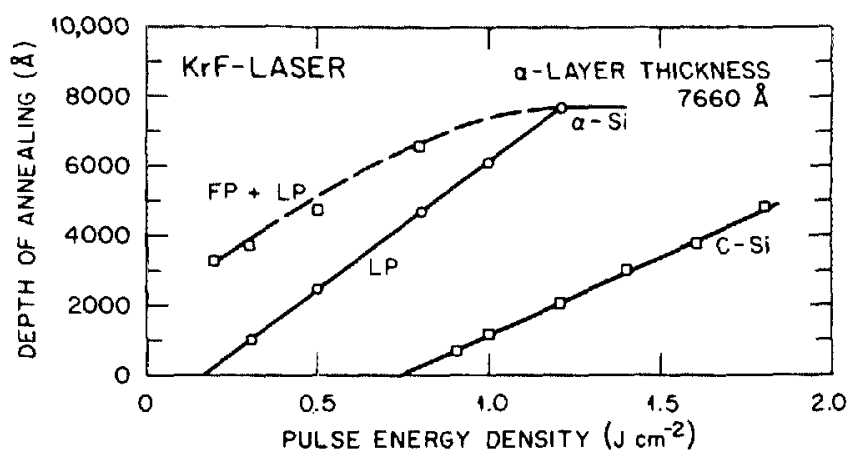

FIG. 4. Depth of annealing as a function of pulse energy density for amorphous and crystalline samples. In the case of amorphous silicon, the thickness of (FP + LP) and LP regions are plotted.

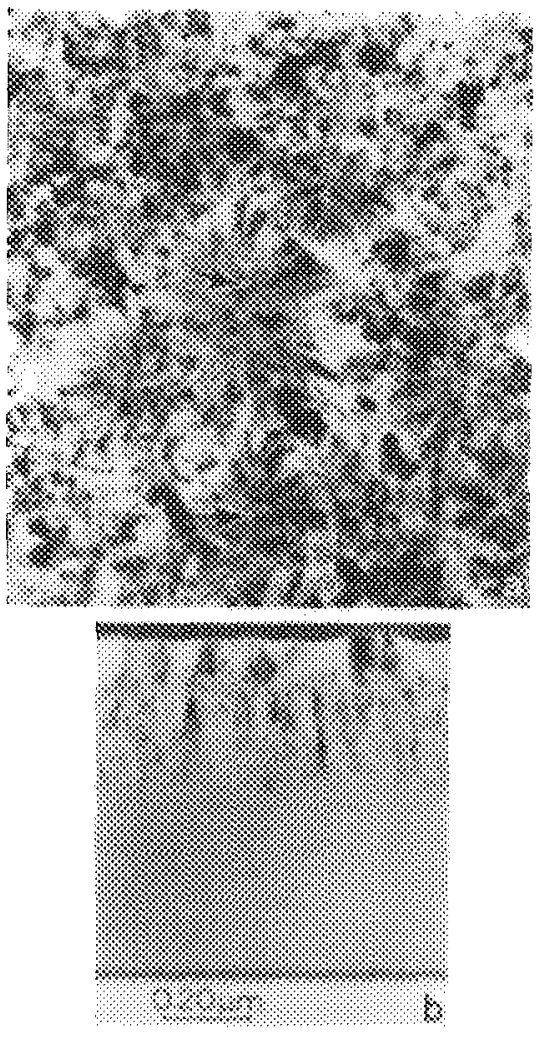

FIG. 5. Plan-view and cross-section TEM micrographs from $\mathrm{Si}^{+}$implants $\left(350-\mathrm{keV}^{28} \mathrm{Si}^{+}, 2.0 \times 10^{16} \mathrm{~cm}^{-2}\right)$, after irradiation with $0.30-\mathrm{J} \mathrm{cm}^{-2}$ pulse.

lization during the formation of the $F R$ region was presented by the authors in a previous paper. ${ }^{5}$ For higher-pulse energy densities where the width of the FP is considerably smaller than that of the LP region, we found equiaxed grains in the FP region, suggesting the possibility of bulk nucleation and growth ${ }^{9}$ in the formation of the FP region. The bulk nucleation is presumably promoted, if there are microcrystallites present in as-implanted amorphous silicon layers. ${ }^{11}$

In conclusion, we have shown that laser pulses from excimer lasers can be efficiently used to remove ion implantation damage in semiconductors by melting the entire damaged layer so that the underlying "defect-free" substrate could act as a seed for crystal growth. The threshold for melting amorphous and crystalline silicon was determined to be $0.16 \pm 0.02$ and $0.75=0.05 \mathrm{~cm}^{-2}$, respectively. In the case of amorphous silicon, above this threshold, two kinds of annealed regions were observed. The large-polycrystalbine (LP) was followed by a fine-polycrystalline (FP) region having $\sim 100-\AA$ grain size. The thickness of the LP region increased linearly with pulse energy density, whereas the thickness of $(F P+L P)$ region showed a rapid initial rise followed by a saturation. The thickness of the $L P$ region as a function of pulse energy density is correctly predicted by the melting model calculations, assuming normal melting from and resolidification back to the free surface. The FP region is formed primarily by explosive recrystallization; however, in certain situations it may be forming by bulk nucleation and growth. The excellent agreement between the experimental results and the calculations on thresholds of melting of amorphous and crystalline silicon are obtained by using re- 
duced melting point, heat of fusion, and thermal conductivity for amorphous compared to crystalline silicon.

\section{ACKNOWLEDGMENT}

We are grateful to $M$. O. Thompson for making his heat-flow program available to us.

'R. T. Young, J. Narayan, W. H. Christie, G. A. van der Leeden, J. I. Levatter, and L. J. Chen, Solid State Technol. 26, 183 (1983).

${ }^{2}$ J. Narayan, O. W. Holland, C. W. White, and R. T. Young, J. Appl. Phys. $55,1125(1984)$.

${ }^{3}$ J. Narayan and C. W. White, Appl. Phys. Lett, 44, 35 (1984).
${ }^{4}$ M. O. Thompson, G. J. Galvin, J. W. Mayer, P. S. Peercy, J. M. Poate, and D. C. Jacobson, Phys. Rev. Lett. (to be published).

${ }^{5}$ J. Narayan, C. W. White, O. W. Holland, and M. J. Aziz, J. Appl. Phys. 56, 1821 (1984).

${ }^{6}$ H. C. Webber, A. G. Cullis, and N. G. Chew, Appl. Phys. Lett. 43, 669 (1983).

'P. Baeri, G. Foti, J. M. Poate, and A. G. Cullis, Phys. Rev. Lett. 45, 2036 (1980).

${ }^{8}$ D. H. Lowndes, R. F. Wood, and J. Narayan, Phys. Rev. Lett. 52, 561 (1984).

${ }^{9}$ R. F. Wood, D. H. Lowndes, and J. Narayan, Appl. Phys. Lett. 44, 770 (1984).

${ }^{10} \mathrm{M}$. O. Thompson, Ph.D. Thesis (Cornell University, 1984).

"J. Narayan, D. Fathy, O. S. Oen, and O. W. Holland, Mater. Lett. 2, 211 (1984). 